\title{
Impact of COVID -19 on the children's hospital of Rabat activities during 2020: General profile and comparison with the year 2019.
}

\author{
Houda Oubejja ${ }^{1,2,3,4}$ Adil Cherkaoui $^{3,5}$, Toualouth Lafia ${ }^{1,2,6}$, Abdelrhani Mokhtari ${ }^{3}$, Abdelmajid Soulaymani ${ }^{3}$, \\ 1- Department of pediatric surgical emergencies, children's hospital of Rabat, Morocco. \\ 2- Faculty of medecine and pharmacy, University Mohammed V, Rabat, Morocco. \\ 3- Laboratory of health and biology, faculty of science, university IbnTofail Kenitra, Morocco. \\ 4- Laboratory of epidemiology, clinical research and Biostatistics, faculty of medecine and pharmacy, University \\ Mohammed V, Rabat, Morocco. \\ 5- Biomedical maintenance service, children's hospital of Rabat, Morocco \\ 6- Ministry of health, republic of Benin.
}

\begin{abstract}
The Covid-19 pandemic has put stress on the healthcare system around the world and has had an impact on people's access to healthcare. This study aims to underline the activities at the Rabat Children's Hospital (HER), during the year 2020 which experienced a state of health emergency due to the Covid-19 pandemic.

Material and methods: We have listed the data from the admission and billing service, about the activities of the hospitalization department of the children's hospital, Rabat. Data was entered on WPS and analyzed by Jamovi software 1.6.23. We also calculated some performance indicators: Average occupancy rate, average length of stay, and bed turnover interval (BOR, LOS, and BTOI). Results: We distinguished between services providing " urgent care" (intensive care unit ICU and emergency rooms ER) and those providing "non-urgent care " (pediatry and surgery) department. The mean number of hospital admissions (NHA) was around 8123 + /- 3942. The average BOR, LOS and BTOI were respectively 72.0 days (SD: 32.6), 66.83 days (SD: 2.68) and 3.89 days (SD: 4.34).

Conclusion : The COVID-19 pandemic had an impact on our hospital activities, disturbing its normal functioning. This study tried to have an overview on the current situation and should lead to other studies in the future, allowing a better managmnt of our hospital.
\end{abstract}

\section{Introduction}

The Covid-19 pandemic has put stress on the healthcare system around the world and has had a variable impact on people's access to healthcare. Like other countries in the world, Morocco has not been spared by the SARS-COV-2 virus pandemic. The first confirmed case of COVID 19 was recorded on March $2^{\text {nd }}$ 2020, Morocco declared a state of health emergency and imposed total containment from March $23^{\text {rd }}, 2020$, which imposed a restriction on the movement of populations and consequently reduced access to hospital services. The aim of this paper is to study variation of hospital activities at Children's Hospital of Rabat (HER), during 2020 and to compare DATA with the previous year, especialy the second and third trimesters.

\section{Material and methods:}

We have listed the data from the registers of admission and billing services, focusing on the activities of the hospitalization departments of children's hospital of Rabat. The patients with COVID-19 were excluded. We also calculated the performance indicators: average length of stay, bed turnover interval (Av BOR, Av LOS, and BTOI). The Average bed occupancy rate BOR (\%) corresponds to the number of days completed per year divided by the number of beds installed and multiplied by 100 . The average length of stay (LOS) corresponds to the number of days completed by the number of admissions. The turnover interval (BTOI) corresponds to average period in days that an available bed remains empty between the discharge of one inpatient and the admission of the next. It's divided by the number of beds installed and multiplied by 100 . The BTOI indicates a shortage of beds when negative, and under-use of the hospital or an inefficient admission system if positive.

The Children's Hospital of Rabat is a tertiary care hospital that is one of the ten health facilities of the Ibn Sina Hospital Center. It is a public health institution, with legal personality and financial autonomy, under the guardianship of the state. It is part of the Mother-Child complex and is a member of the Mother-Child Network of the "Francophonie". Founded in 1977, it is the first pediatric hospital in the kingdom, therefore the oldest and most important in terms of capacity among the 4 public university hospitals in the kingdom. It is organized in several sectors: emergency department, intensive care unit, hospitalization services and technical platform (Radiology, laboratory of biology and anatomopathology). The hospital has 5 pediatric departments (PI,PII,PIII, PIV and Pv which is devided into 2 units : neonatology unit and neonatal intensive care unit). The CHOP, pediatric hemato-oncology center is an independent service dealing with pediatric cancers. Furthermore, there is 4 surgical departments: A,B, C and the PSE department (ER). Finaly one pediatric intensive care (PICU) admitting kids over 2 months old while de neonat ICU is dedicated to newborns to 2 months. We have distinguished department providing "non-urgent" care activities (Pediatrics and surgery) and the ones providing "urgent" care (Resuscitation services ICU and emergency rooms ER). We collected the data from the 
$2^{\text {nd }}$ and $3^{\text {rd }}$ quarters of the year 2020 (during the national containment and immediately after) and we compared it with the data from the same period of the year 2019. These data was entered on WPS and analyzed by Jamovi software 1.6.23. The qualitative variables were expressed in number and percentage and the quantitative variables in mean $+/$ - standard deviation.

\section{Results}

The number of total hospitalisation of children's hospital was arround 97481 admission in 2020. The median of number of hospitalisation over different department was $8123+/-3942$. The table 1 shows the median of the perfomance indicators all services combined.

Table 1: The median of the number of hospital admission per year and the perfomance indicators all services combined, children's hospital of Rabat, 2020.

\begin{tabular}{lcccc}
\hline $\begin{array}{l}\text { Performance } \\
\text { indicators }\end{array}$ & NHA & $\begin{array}{c}\text { Av BOR } \\
(\%)\end{array}$ & $\begin{array}{c}\text { Av } \\
\text { LOS } \\
(\mathrm{d})\end{array}$ & $\begin{array}{c}\text { BTOI } \\
(\mathrm{d})\end{array}$ \\
\hline Total & 97481 & 64,18 & 6,07 & 3,39 \\
Mean +/-SD & $8123+/-$ & $72.0+/-$ & $6.83+/-$ & $3.89+/-$ \\
& 3942 & 32.6 & 2.68 & 4.34 \\
Minimum & 3760 & 30.2 & 3.41 & -1.68 \\
Maximum & 15156 & 147 & 11.4 & 13.9
\end{tabular}

NHA/Y: number of Hospital admission/year; Av BOR : Average Bed occupancy rate, Av LOS (d): Average length of stay; BTOI: Bed Turnover Interval

The activity of different departments is shown in the figure 1. Indeed, the total number of hospital admission and the performance indicators are different from one service to another according to their specialities.

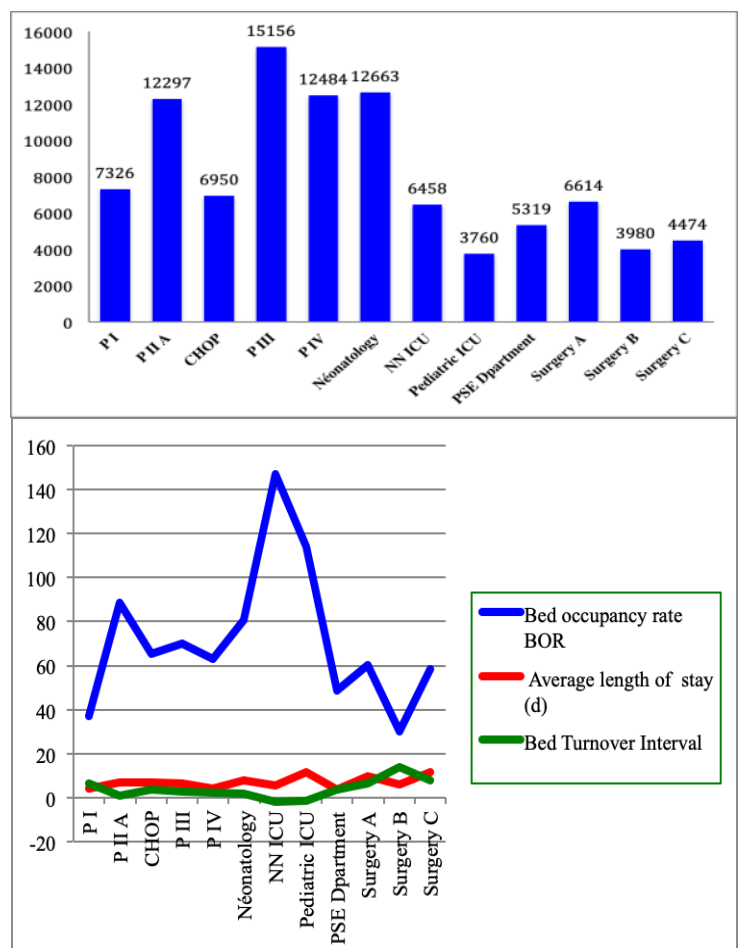

Figure 1 showing the number of hospital admissions and the performance indicators according to departments, children's hospital of Rabat, 2020.
The table 2 summarizes the indicators according to the « urgent» care or «non-urgent» care provided. It undelines the fact that the «non-urgent» services decreased their activities between the first and second quarters of the year 2020 with a slight increase during the $3^{\text {rd }}$ and $4^{\text {th }}$ trimester.

Furthermore, we also compared the DATA with the last year ones. Thus, the decrease of the mean NHA and the indicators ranges from $-3 \%$ to $-29 \%$ (Table 3 ). The hospital activities experienced some differences over the two years. Indeed, comparing the data for the second quarter between 2020 and 2019, the "non urgent care" departement, regardeless of their specialities, experienced a drop in performance indicators (Table 4). Moreover, the emergencies department as well as ICU noticed a slight decrease in the number of admission and the length of stay (respectively $-26 \%$ and $-55 \%$ during the second quarter vs $-16 \%$ and $-43 \%$ during the $3^{\text {rd }}$ quarter).

Table 3: Comparison of the median of the number of hospital admission and the perfomance indicators all services combined, between 2020 and 2019, children's hospital of Rabat.

\begin{tabular}{|l|c|c|c|c|}
\hline $\mathbf{2 0 2 0}$ & \multicolumn{4}{|c|}{} \\
\hline $\begin{array}{l}\text { Performance } \\
\text { indicators }\end{array}$ & NHA & $\begin{array}{c}\text { Av BOR } \\
(\%)\end{array}$ & $\begin{array}{c}\text { Av LOS } \\
(\mathrm{d})\end{array}$ & $\begin{array}{c}\text { BTOI } \\
(\mathrm{d})\end{array}$ \\
\hline Total & 97481 & 64,18 & 6,07 & 3,39 \\
\hline Mean +/-SD & $\begin{array}{c}8123+/- \\
7942\end{array}$ & $\begin{array}{c}72.0+/- \\
32.6\end{array}$ & $\begin{array}{c}6.83+/- \\
2.68\end{array}$ & $\begin{array}{c}3.89+/- \\
4.34\end{array}$ \\
\hline $\mathbf{2 0 1 9}$ & & & & \\
\hline Total & 119972 & 79,6 & 6,3 & 1,6 \\
\hline Mean +/-SD & $\begin{array}{c}9998+/- \\
7142\end{array}$ & $\begin{array}{c}78.3+/- \\
22,1\end{array}$ & $\begin{array}{c}7.05 \\
(2,79)\end{array}$ & $\begin{array}{c}3.01 \\
(3,70)\end{array}$ \\
\hline Variation & $\mathbf{- 1 9 \%}$ & $\mathbf{- 8 \%}$ & $\mathbf{- 3 \%}$ & $\mathbf{2 9 \%}$ \\
\hline
\end{tabular}

NHA/Y: number of Hospital admission/year; Av BOR: Average Bed occupancy rate, Av LOS (d) : Average length of stay; BTOI: Bed Turnover Interval

Table 4: Comparison of the number of hospital admission and the perfomance indicators according to "urgent» or «nonurgent » care provided, between 2020 and 2019 children's hospital of Rabat.

\begin{tabular}{|c|c|c|c|c|}
\hline & $\begin{array}{l}\text { Variation } \\
\text { of NHY }\end{array}$ & $\begin{array}{l}\text { Variation } \\
\text { of BOR }\end{array}$ & $\begin{array}{l}\text { Variation } \\
\text { of LOS }\end{array}$ & $\begin{array}{l}\text { Variation } \\
\text { of BTOI }\end{array}$ \\
\hline $\begin{array}{l}2^{\text {nd }} \text { trimester } \\
\text { between } \\
2019 / 2029\end{array}$ & & & & \\
\hline $\begin{array}{l}\text { « Non urgent » } \\
\text { pediatric care }\end{array}$ & $-52 \%$ & $-40 \%$ & $-46 \%$ & $600 \%$ \\
\hline $\begin{array}{l}\text { "Non- } \\
\text { urgent » surgical } \\
\text { care }\end{array}$ & $-53 \%$ & $-57 \%$ & $-93 \%$ & $1146 \%$ \\
\hline $\begin{array}{l}\text { Emergencies } \\
\text { (ICU and ER) }\end{array}$ & $-26 \%$ & $4 \%$ & $-55 \%$ & $53 \%$ \\
\hline $\begin{array}{l}\text { 3rd trimester } \\
\text { between } \\
2019 / 2029\end{array}$ & & & & \\
\hline $\begin{array}{l}\text { «Non urgent » } \\
\text { pediatric care }\end{array}$ & $-28 \%$ & $-30 \%$ & $-6 \%$ & $983 \%$ \\
\hline $\begin{array}{l}\text { «Non- } \\
\text { urgent » surgical } \\
\text { care }\end{array}$ & $-36 \%$ & $-35 \%$ & $-91 \%$ & $13 \%$ \\
\hline
\end{tabular}




\begin{tabular}{l}
$\begin{array}{l}\text { Emergencies } \\
\text { (ICU and ER) }\end{array}$ \\
\hline NHA/Y: number of Hospital admission/year ; Av BOR: Average Bed \\
occupancy rate, Av LOS $($ d $):$ Average length of stay; \\
Turnover Interval : Bed
\end{tabular}

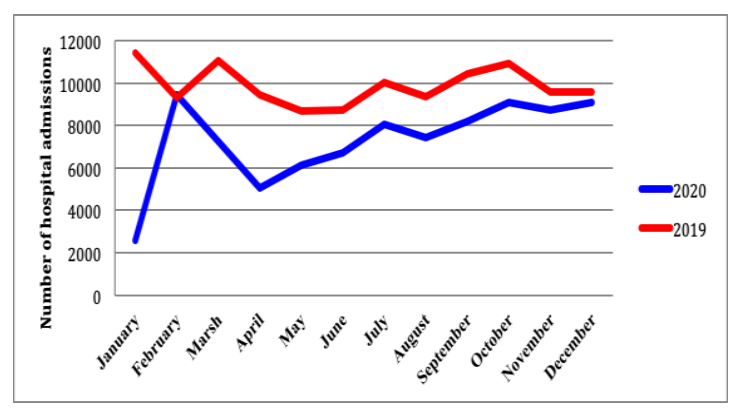

Figure 2 showing the total number of hospital admission in 2020 and 2019, children's hospital of Rabat.

From February 2020, the number of hospital admission fell sharply to reach its minimun in April. The late May showed a slight rebound until July, after which there is a substantial drop during August, with a second rebound which continues until the end of the year.

Regarding the variations according to the quarters, we noticed the same tendency which is a decline followed by a constant but slight increase (Figure 3 ).

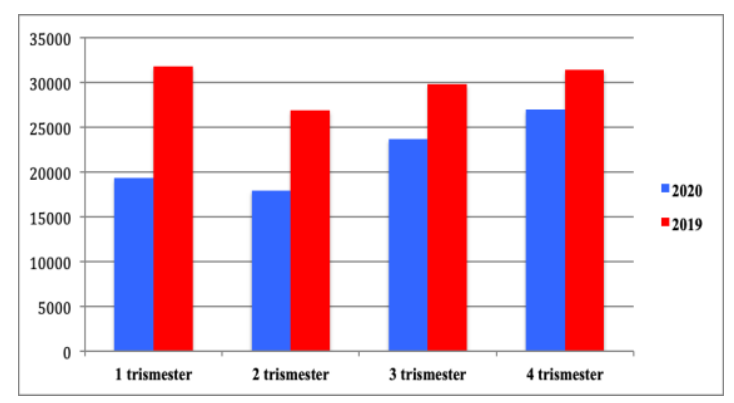

Figure 3: Comparison of number of hositalisation between 2019 and 2020 according to the quarters, children's hospital of Rabat.

\section{Discussion}

Our analysis does not include specific diagnoses to assess which types of admissions had declined, we focused only on some performance indicators, which were number of hospital admission, occupancy rate, average length of stay and bed turnnover interval.

We separately analyze non-COVID-19 admissions both overall and by the «urgent» or «non urgent» care provided. In fact, the number of hospital admission declines worldwide [1-5]. Health professionals have faced the arrival of Covid-patients and the disturbance caused in the traditional activities of the hospitals. Thus, Heist and al [4] reported that the decrease in hospital admissions from March to December 2020 represent $8.5 \%$ of the total expected admissions for all of 2020 . Moreover, the total hospital admissions dropped to
$69.2 \%$ of predicted admissions during the week ending April 20 [4]. In our study, the total decrease was arround $-19 \%$, reaching - 53\% for the number of admission for « non-urgent » department. The emergencies department have seen a decline of the number of hospital admission around $-26 \%$. This result is lower than two studies $[5,6]$, where the decline was around $-42 \%$ to $-50 \%$ from Marsh and April. It rose slowly to $-16 \%$ by the end of June [6]. Obviously, a good hospital management includes an effective allocative planning for beds in a hospital [7]. The average bed occupancy rate (BOR) reflects efficiency in the use of hospital beds. Hospital can be said to be operating efficiently at BOR of $80-90 \%$ [710]. This rate varies depending on the country but also depending on the hospital's healthcare mission and capacities. It ranged from $42 \%$ to $78,8 \%[7,8,11,12]$.

Our study showed an average BOR equal to $64,18 \%$ in 2020 vs $79,6 \%$ in 2019 , which corresponds to $-8 \%$ decline. Regarding the variation between 2020 and 2019, according the trimesters and the " non-urgent or urgent health care», we noted a decline ranging from $-57 \%$ to $-40 \%$ during the second trimester (The lockdown period), while there is a slight improvment reaching $-30 \%$ right after. Otherwise, the emergencies and ICU experienced an increase in the average BOR around $4 \%$ in the 2 quarter, versus $26 \%$ during the $3^{\text {rd }}$ quarter.

The second indicator was the lenght of stay (LOS), it refers to the number of days each admitted patient stayed in the hospital. A short LOS could be regarded as an indicator of hospital efficiency. In 2018, the average length of stay in hospitals for all causes of hospitalisation was 7,5 days across some european countries [13], while it was about 8,15 days in some african countries [8,14].

Our result reported an average length of stay around 6,07 days in 2020, versus 6,3 days for the last year. This result is correlated to the hospital policy aiming to reduce the lenght of stay, to focus on potential Covid19 's patients.

Last but not least, the turnover interval (BTOI) referred to a measurment of the average times or days that hospital beds are unoccupied between successive inpatients. The ideal turnover interval is suggested to be $1-3$ days $[8,15]$, but depends among other things on the bed capacity of the hospital. Our total BTOI was equal to 3,39 days in 2020 comparing to 1,6 days in 2019 . When regarding the variation between the urgent or non-urgent department, emergencie's department had the shortest BTOI all over the trimesters comparing to the other services, which indicates that this department kept almost constant levels during 2020. Otherwise, the comparison with the previous year highlighted a positive increase.

This results can be explained by two things: In one hand, the total lockdown imposed by the governement 
reducing all displacement of the populations and the public fear of COVID-19 contagion [1]. On the other hand, some policy choices made in order to create capacity for COVID-19 patients or to protect nonCOVID patients and staff, led to cancelling planned operations and the movement of most primary care appointments to the telephone or online [16-18]. Like other countries, the Moroccan health ministry has encouraged the reduction and cancellation of non-urgent interventions and consultations. The hospital postponed all elective and semi-urgent interventions. An elective circuit was set up in the premises of the hospital for covid-19's patients which is not included in our study. The patients presenting an «urgent» case consult directly to the emergency room (ER) and if they are suspected of COVID-19, they benefit from a covid-test and will be hospitalized in the area reserved for covid-19 if positive. If surgery is indicated, all the precautions are taken, according to the health ministry recommandations.

Otherwise, this study has limits. First, the number of COVID-19 patients who had monopolized almost the hospital activities is excluded, second, some units were partialy closed which had an impact on different indicators. Thus, all these results must be interpreted with caution so as not to draw hasty conclusions about a hospital malfunction.

\section{Conclusion:}

The COVID-19 pandemic had an impact on our hospital activities, disturbing its normal functioning. This study tried to have an overview on the current situation and should lead to other studies in the future, allowing a better managment of our hospital in crisis context. 


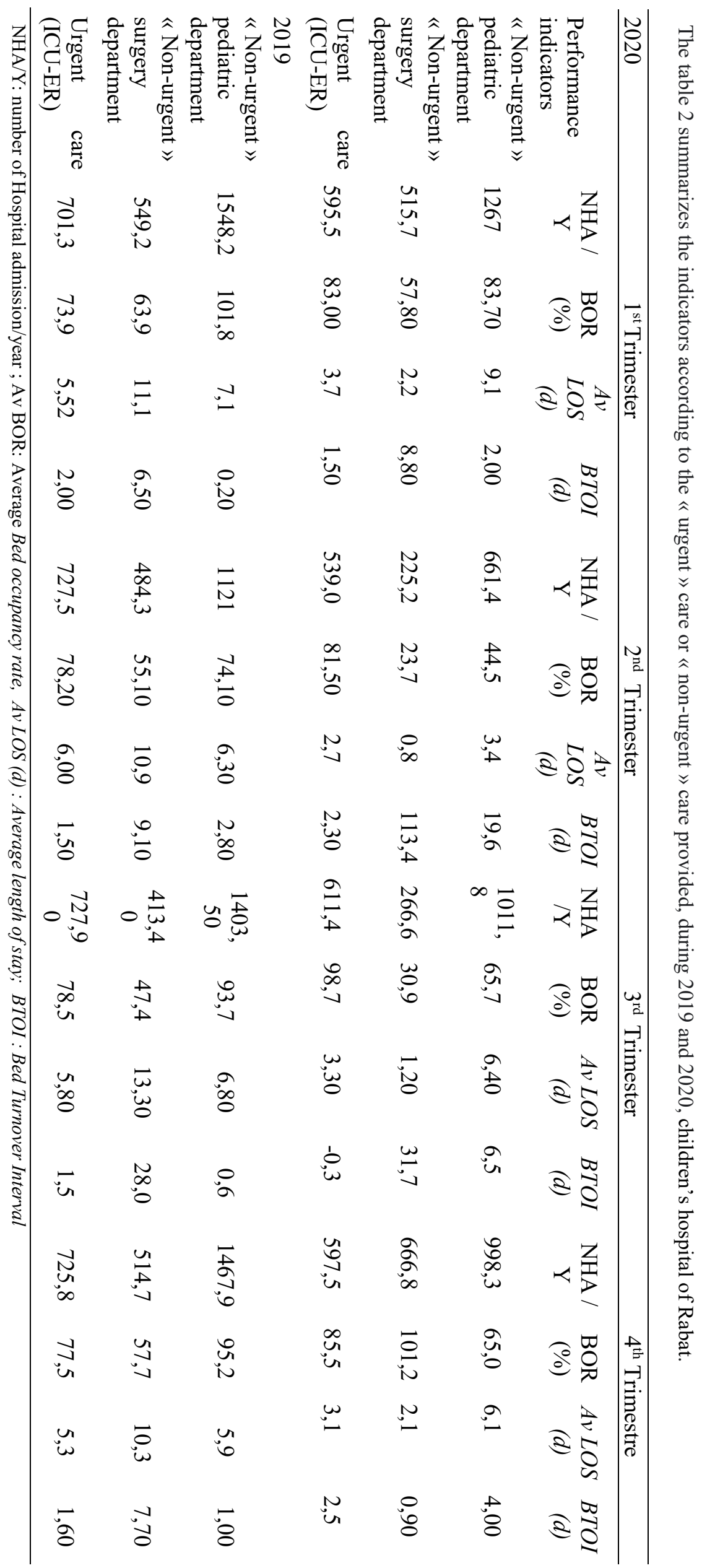




\section{References}

1. J D. Birkmeyer, A. Barnato, N. Birkmeyer, R. Bessler, and J. Skinner. The Impact Of The COVID-19 Pandemic On Hospital Admissions In The United States. HEALTH AFFAIRS 39, ;sEpi NO. 11 2010-2017(2020):

2. C. Cox, R. Kamal, D. McDermott. How have healthcare utilization and spending changed so far during the coronavirus pandemic? [Internet]. San Francisco (CA): Peterson-KFF Health System Tracker; Aug 6(2020). Available from: https://www.healthsystemtracker .org/chartcollection/how-have- healthcare-utilizationand-spending- changed-so-far-during-thecoronavirus-pandemic/ (2020) istep:

3. KP. Hartnett, A. Kite-Powell, J. DeVies, MA. Coletta, TK. Boehmer, J. Adjemian, et al. Impact of the COVID-19 pandemic on emergency department visits-United States, January 1，2019-May 30, 2020. MMWR Morb Mortal Wkly Rep. 2020; 69 (23): 699704 istep: (2020).

4. T.Heist,K. Schwartz, and S.Butler. Trends in Overall and Non-COVID-19 Hospital Admissions. Published: Feb 18, (2021)

5. KP. Hartnett, A. Kite-Powell, J. DeVies, MA. Coletta, TK. Boehmer, J. Adjemian, AV. Gundlapalli. Impact of the COVID-19 Pandemic on Emergency Department Visits - United States, January 1, 2019-May 30, 2020, Control and Prevention MMWR / June 12, 2020 / Vol. 69 / No. 23 (2020)

6. COVID-19's effect on hospital care services on https://www.cihi.ca/en/covid-19resources/impact-of-covid-19-on-canadashealth-care-systems/covid-19s-effect-onhospital.

7. G. Usman, KN. Memon, S.Shaikh. Bed occupancy rate and length of stay of patients in medical and allied wards of a tertiary care hospital. J Ayub Med Coll Abbottabad. 2015 apr-jun; 27(2):367-70. pmid: 26411118 (2015).

8. H.E. Aloh, O.E. Onwujekwe, O.G. Aloh et al. Is bed turnover rate a good metric for hospital scale efficiency? A measure of resource utilization rate for hospitals in Southeast Nigeria. Cost Eff Resour Alloc 18, 21 (2020). https://doi.org/10.1186/s12962-020-00216-w (2020)

9. H. Ni Barnum, J. Kutzin. Public hospitals in developing countries: Resource use, cost, financing. Baltimore: Johns Hopkins University Press; (1993).

10. F. Madsen, S. Ladelund, and A. Linneberg. High Levels Of Bed Occupancy Associated With Increased Inpatient And Thirty-Day Hospital Mortality In Denmark Health Affairs July 2014 33:7 (2014).
11. M. NabuKeera, A. Boerhannoeddin, RA. Raja Noriza. An evaluation of health centers and hospital efficiency in Kampala capital city authority Uganda: using Pabon Lasso technique. J Health Transl Med. 2015;18 (1):12-7.https ://doi.org/10.5430/wjss.v1n2p86. (2015)

12. M. Ghobad, P. Bakhtiar, S. Hossein, EN. Nader, MB. Amjad, Y. Arezoo. Assess- ment of the efficiency of hospitals before and after the implementation of Health Sector Evolution Plan in Iran Based on Pabon Lasso Model. Iran J Public Health. 2017;46 (3):38995. (2017)

13. Resilience: innovation, efficiency and fiscal sustainability, health at a glance: europe 2018 (C) oecd/european union OECD/EUROPEAN UNION (2018)

14. H. Ravaghi, M. Afshari, P. Isfahani, \& VD. Bélorgeot. A systematic review on hospital inefficiency in the Eastern Mediterranean Region: sources and solutions. BMC Health Services Research, 19(1). doi:10.1186/s12913-019-47011 (2019).

15. JB. Cunningham, WG. Kernohan, R. Sowney. Bed occupancy and turnover interval as determinant factors in MRSA infections in acute settings in Northern Ireland: 1 April 2001 to 31 March 2003. J Hosp Infect. 2005 Nov;61 (3):189-93. doi: 10.1016/j.jhin.2005.04.014. Epub 2005 Sep 8. PMID: 16153745 (2005).

16. Elaine Kelly, Zoe Firt. How is COVID-19 changing the use of emergency care ?on https://www.health.org.uk/news-andcomment/charts-and-infographics/how-iscovid-19-changing-the-use-of-emergencycare.

17. Un système de santé focalisé sur une pathologie au détriment des autres : une crise sanitaire en cache-t-elle une autre? Santé publique: pour un nouveau départ-leçons de l'épidémie de covid-19- Rapport. on http://www.senat.fr/rap/r20-199-1/r20-199111.html

18. F. Pecoraro, D. Luzi, F. Clemente. The efficiency in the ordinary hospital bed management: A comparative analysis in four European countries before the COVID-19 outbreak. PLoS ONE 16(3): e0248867. https://doi.org/ 10.1371/journal.pone.0248867 (2021). 